\section{The specific notion}

\section{Fred S. Rosen}

Exquisite Specificity: The Monoclonal Antibody Revolution. By Alberto Cambrosio and Peter Keating. Oxford University Press: 1996. Pp. 243. £39.50, \$59.95.

EVER since Dr Charles McIntyre collected a urine specimen from a greengrocer with myeloma in Devonshire Street, London, in 1846 , the study of the disease has been a productive route to discovery. McIntyre, thinking that the greengrocer's urine would contain protein ("animal matter") because he was losing weight rapidly, heated the urine and found that a precipitate formed between $45^{\circ} \mathrm{C}$ and $60{ }^{\circ} \mathrm{C}$, which redissolved when the urine was boiled. He then sent this urine specimen to Professor Henry Bence-Jones, at Guy's Hospital, asking "What is this?". Bence-Jones never answered, but the precipitate nevertheless became known as Bence-Jones protein. It was only the second protein to be obtained in pure form (the first having been hen egg albumin). It was more than a century later that Bence-Jones proteins were identified as the light chains of immunoglobulins.

Myelomas are tumours of plasma cells, usually in the bone marrow. They are found in many species, and can be induced in mice by intraperitoneal injection of mineral oil. Myeloma proteins, which are immunoglobulins secreted by malignant plasma cells, eventually helped to solve problems of immunoglobulin genetics and structure. Gerald Edelman shared the Nobel Prize for Physiology or Medicine in 1972 after completing the sequence of a myeloma protein, $\mathrm{Eu}$, the first immuno-globulin to be sequenced completely.

In 1975, a landmark paper was published by Georges Köhler and César Milstein (Nature 256, 495; 1975). These investigators fused mouse myeloma cells with splenic lymphocytes from a mouse that had been immunized with sheep red blood cells. The immortalized hybrid cells now produced prodigious quantities of pure monoclonal antibodies to sheep red blood cells. Standardized reagents, hitherto unknown in immunology, were now available. Several immunologists in the early 1970s were trying to establish monoclonal antibody production by transformed cells, but Köhler and Milstein were the first to succeed.

They grasped the power of this new tool, but could not anticipate that it would spawn a multimillion-dollar biotechnology industry, which came about largely because of the almost simultaneous development of the fluorescence-activated cell sorter. Monoclonal antibodies worth $\$ 574$ million are said to have been sold in the United States alone in 1992. This transformation of a simple and beautiful discovery into a vast biotechnology industry is now recounted by Alberto Cambrosio and Peter Keating in Exquisite Specificity. It is in many respects a sordid tale of specious claims to priority, lawsuits and countersuits, and distortions of science funding that do little credit to the scientific community, and even less to the biotechnology industry. The story is well told in this book.

If Köhler and Milstein had patented their finding, a great deal of grief might

\section{IMAGE \\ UNAVAILABLE FOR COPYRIGHT REASONS}

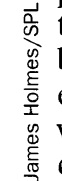

के tists, as well as examples of collaboration,

bitter competition and a few cases of deliberate deception. These events are deftly woven together to illustrate the unpredictable nature of the scientific endeavour and how disparate areas of research can unexpectedly converge to provide new insights and models. Some of these stories are tedious, especially the lengthy descriptions of the research in Weinberg's own laboratory. But he did make important discoveries; this is his book, and he is not a modest man.

It is not apparent why, in glorifying the contributions of molecular biology to cancer research, the author finds it necessary to bash other disciplines, especially as the title of the book promises to take us "down the road", and not just one of the paths, in the search for the origins of cancer. For example, in an early chapter entitled "A can of worms" he states that by the 1960s the field of chemical carcinogenesis had reached an impasse and researchers in this field "became increasingly demoralized, seeing no clear way to advance their work". But for those of us who were there, this field was and still remains an exciting area of cancer research - and not because we are on Prozac.

Major discoveries were made, including the principles of metabolic activation and detoxification of carcinogens, the structures and mutagenicity of specific carcinogen-DNA adducts, the role of DNA repair as a host defence mechanism and basic principles of tumour promotion and hormonal carcinogenesis. These findings also provide profound insights into the origin of cancer, including the origin of specific mutations in ras oncogenes and the p53 tumour-suppressor gene.

Weinberg glosses over these accomplishments by numerous investigators in the United Kingdom, the United States, Japan and elsewhere, and instead states that Bruce Ames's aphorism in 1979 that carcinogens are mutagens "had become the credo of our religion", even though in recent years Ames has backed away from this equation, recognizing that it is an over- 


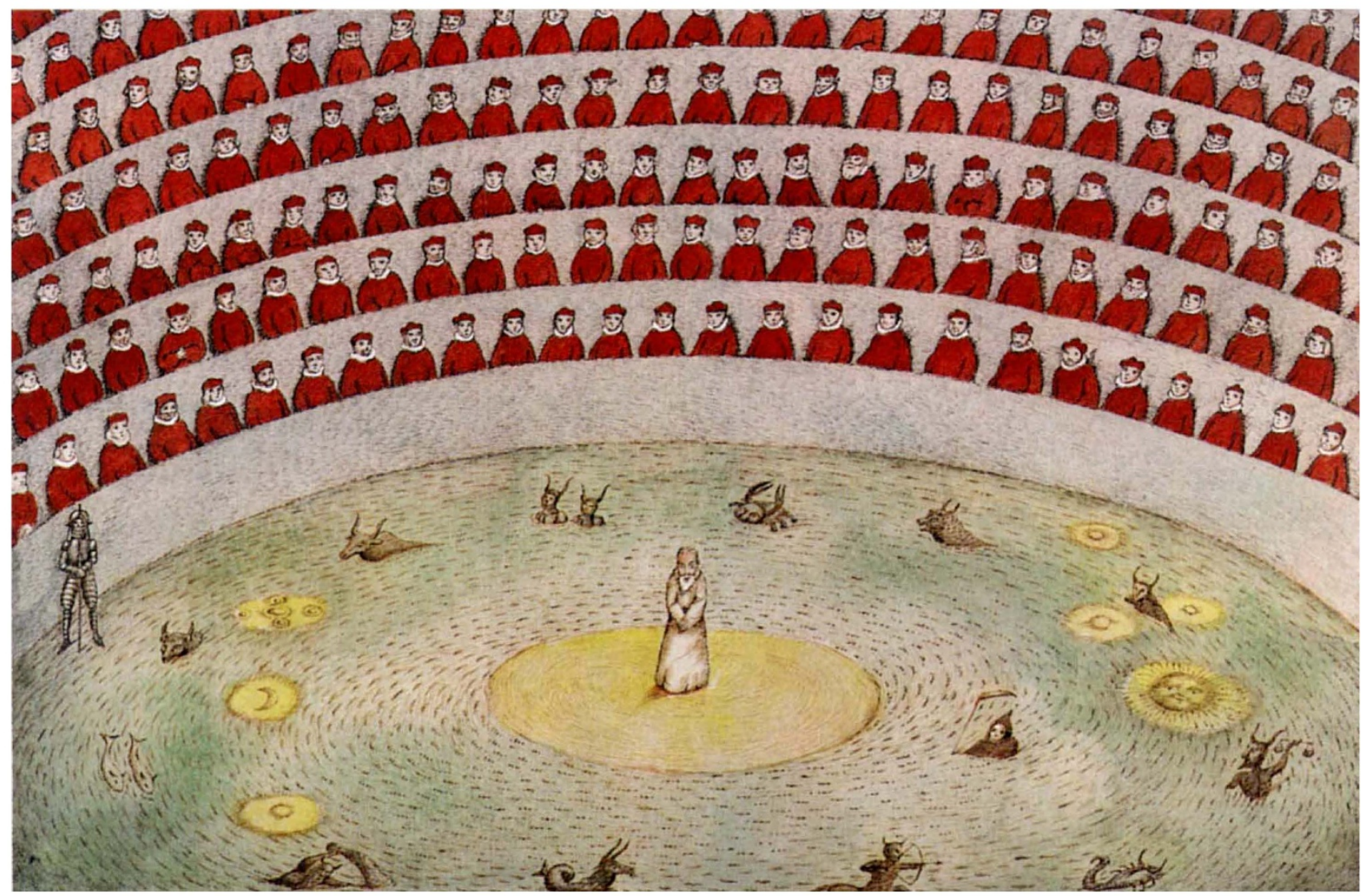

In his enchantingly illustrated children's book Starry Messenger, Peter Sis, an internationally acclaimed illustrator and film maker, tells the story of the life of Galileo. Its publication today comes exactly four years after the Vatican's rehabilitation of the grand old man. Farrar, Straus and Giroux, $\$ 16$.

simplification. Indeed, Weinberg's initial discovery of mutated cellular oncogenes was made possible by the use of well-characterized carcinogen-transformed cells developed by investigators in the field of chemical carcinogenesis.

Also, in an early chapter, he asserts that research on viruses and cancer "threatened to divert a rapid forward thrust straight into another patch of very deep mud." And yet, later in his book, Weinberg recognizes that research on tumour viruses has had an enormous pay-off, including the discovery of reverse transcriptase, the roles of hepatitis $\mathrm{B}$ and $\mathrm{C}$ viruses in liver cancer, of Epstein-Barr virus in Burkitt's lymphoma, of human papilloma virus in cervical cancer, of a retrovirus (HTLV-1) in one form of lymphoma, and the viral origin of AIDS and AIDS-related malignancies. Not a bad record for a field mired in the mud. Furthermore, some of us would not be surprised to learn that viruses or other infectious agents have a role as cofactors in the origin of other types of cancer.

Weinberg is also merciless in his criticisms of those who have emphasized epigenetic mechanisms in carcinogenesis, even though there is substantial evidence that both epigenetic abnormalities and mutagenesis play important parts in the multistep process of carcinogenesis. He also glosses over the recent advances made in cancer immunology, cancer biology (apoptosis, angiogenesis, invasion and metastasis) and epidemiology. He does, however, acknowledge the importance of clinical and epidemiological studies in revealing cigarette smoking (a source of chemical carcinogens) as the cause of lung cancer. Perhaps this is because he claims Ernst Wynder, but not of course Sir Richard Doll, as a distant relative.

In the euphoria surrounding recent advances in the molecular biology of cancer, we must remain sober about the limitations in translating our knowledge and accomplishments into more effective strategies for cancer prevention and treatment. We still lack hard facts about the exogenous factors that cause cancers of the breast, prostate and colon, even though today they account for about half of new cancer cases in the United States and Western Europe and their incidence is increasing in other countries. Although dietary factors have been implicated, experts in the field disagree on the precise components and the underlying mechanisms.

Within the mechanistic framework of oncogenes and tumour-suppressor genes, the multistep evolution of cancer cells seems to be much more complex than was originally thought when the first oncogenes were discovered. We now know that a given tumour often carries several mutated genes as well as gross chromosomal abnormalities, that more than a hundred different genes have been found to be mutated and/or abnormally expressed in various types of human cancer and that each year this list gets longer. The biochemical functions of these genes are extremely diverse, and encompass intracellular circuitry involved in signal transduction, gene transcription, cell-cycle control, DNA replication and repair, differentiation, senescence and apoptosis, as well as extracellular functions related to cell-cell and cell-matrix interactions, proteases, locomotion and angiogenesis.

These complexities do not of course detract from the recent progress properly celebrated in Weinberg's book. They do, however, indicate the need for greater modesty and for the development of more holistic and multidisciplinary approaches in cancer research that will complement the reductionist approaches emphasized in the past few decades.

1. Bernard Weinstein is at the College of Physicians and Surgeons, Columbia University, 701 West 168th Street, New York, New York 10032, USA. 